\title{
Systematic review and meta-analysis of PIT tagging effects on mortality and growth of juvenile salmonids
}

\author{
Knut Wiik Vollset $\mathbb{D} \cdot$ Robert J. Lennox - Eva B. Thorstad - Samuel Auer • \\ Kerstin Bär • Martin H. Larsen · Shad Mahlum • Joacim Näslund • \\ Henrik Stryhn · Ian Dohoo
}

Received: 2 April 2020/ Accepted: 2 July 2020/Published online: 18 October 2020

(C) The Author(s) 2020

\begin{abstract}
A systematic review and meta-analysis was conducted to evaluate the appropriate tag:fish size ratio when tagging juvenile salmonids (genera $\mathrm{On}^{-}$ corhynchus, Salmo, and Salvelinus). The review yielded 18 publications with 211 control and treatment groups reporting results from laboratory studies on the effects of passive integrated transponder (PIT) tags, plus a small number of additional studies on acoustic transmitters. A meta-analysis of the PIT tagging studies showed significant heterogeneity among
\end{abstract}

Electronic supplementary material The online version of this article (https://doi.org/10.1007/s11160-020-09611-1) contains supplementary material, which is available to authorized users.

K. W. Vollset $(\bowtie) \cdot$ R. J. Lennox $\cdot$ S. Mahlum LFI - Freshwater Biology, NORCE Norwegian Research Centre, Nygardsporten 112, 5006 Bergen, Norway e-mail: knvo@norceresearch.no

\section{E. B. Thorstad}

Norwegian Institute for Nature Research, P.O. box 5685, Torgarden, 7485 Trondheim, Norway

\section{S. Auer}

University of Natural Resources and Life Science, Gregor-Mendel-Straße 33, 1180 Vienna, Austria

K. Bär

Technical University of Munich, Emil-Ramann-Str.6, 85354 Freising, Germany studies with respect to mortality. Meta-regression revealed that juvenile salmonid mortality increased curvilinearly with the tag:fish length ratio, indicating that mortality risk is rapidly enhanced as smaller fish or larger tag sizes are used. The tag:fish length ratio effect on daily length or mass gain increased linearly. The results provide an estimate of the effects of the tag:fish length ratio on mortality and growth parameters in juvenile salmonids. Based on this, we suggest that researchers can follow best practices for tagging juvenile salmonids with tags that are not greater than $17.5 \%$ of fish total length (TL). This equates a minimum size threshold of $131 \mathrm{~mm}$ TL for tagging salmonids with 23-mm PIT tags, and $69 \mathrm{~mm}$ TL with

\author{
M. H. Larsen \\ Danish Centre for Wild Salmon, Brusgårdsvej 15, \\ 8960 Randers SØ, Denmark \\ J. Näslund \\ Department of Aquatic Resources, Institute of Freshwater \\ Research, Swedish University of Agricultural Sciences, \\ Stångholmsvägen 2, 17893 Drottningholm, Sweden \\ H. Stryhn · I. Dohoo \\ University of PEI, 550 University Ave, Charlottetown, \\ PEI C1A 4P3, Canada
}


12-mm PIT tags. This information can assist researchers, managers, and welfare agencies striving to use the best possible evidence to make informed decisions regarding fish tagging.

Keywords Acoustic - Tag effects - Passive integrated transponder $\cdot$ Salmon $\cdot$ Trout $\cdot$ Mortality

\section{Introduction}

Given their ecological and cultural importance (Verspoor et al. 2008; Forseth et al. 2017), salmonids have been important focal species of tagging efforts for centuries (Walton 1653). Studying salmonids by use of electronic tags has given insight into freshwater migration patterns (Økland et al. 2001; Richard et al. 2014), freshwater ecology and behaviour (Roussel et al. 2000), impacts of hydropower production (Aarestrup et al. 2003; Burnett et al. 2014), impacts of fisheries (Raby et al. 2012), mechanisms and causes of mortality (Cooke et al. 2006; Källo et al. 2020), and areas of marine residence (Spares et al. 2012; Strøm et al. 2018). Many electronic tag types exist with different advantages and disadvantages, often with a tradeoff between tag size and tag performance (Thorstad et al. 2013). Larger tags generally have broader detection ranges than smaller tags. Small tags can be used in comparatively small fish and potentially have lesser impact on the animals' performance in terms of growth, survival, and behaviour, but usually have shorter detection ranges, and depending on the type may have short life span.

Effects of the tagging process and physical impacts of tags themselves on animal health and performance, and consequently, the validity of study results, have been of scientific interest since tagging became a common practice among fisheries scientists (e.g. Markus 1933; Pechacek 1956; Jepsen et al. 2015). Common statistical methods for analyzing telemetry data rely on the assumption that tagged individuals are representative of the studied population. Consequently, data from individuals negatively affected by tagging may provide false inferences about growth, survival rates, and behaviour of wild fish. Procedures such as capture, handling, and tagging elicit physiological and behavioral responses of animals, and the tagged individual requires time and suitable conditions to recover. Some animals may not survive the stress associated with tagging or carrying the tag may be exceptionally burdensome (Rasiulis et al. 2014; Vandenabeele et al. 2015). Long-term impacts may also include tissue infections around the tagging incision that result in mortality (Adams et al. 1998; Larsen et al. 2013). Tertiary stress responses can manifest as altered growth, immune responses, and reproductive success (Wendelaar Bonga 1997), which have direct consequences for the lifetime fitness of tagged animals.

Passive integrated transponder (PIT) tags have been used extensively for individual fish monitoring throughout the world, and the popularity of this tag has increased since their introduction in the mid-1980s (Gibbons and Andrews 2004). PIT-tags are relatively cheap, small, long-lasting, and require simple tagging procedures (i.e., non-surgical; Smyth and Nebel 2013). The advantage of these tags compared to other telemetry tags is that they are small because they do not carry a battery. Instead of the tag producing an active signal, an internal microchip in the tag is activated when the tag passes through an electrical field, thus transmitting a unique ID to a reader where the detection and associated information is stored. The small size and long life of the tags make this technology particularly suitable for studies of survival and recruitment of long-lived animals such as salmon that migrate to the sea at a small body size and return to their home river to spawn after one to several years at sea. Another widely applied telemetry tagging method for juvenile salmonids is the use of small acoustic transmitters. These tags are generally larger and heavier than PIT-tags because they depend on an internal battery to actively transmit sound signals at a certain interval (usually 30-90s). Signals from acoustic tags are recorded by receivers within a range of approximately $100-500 \mathrm{~m}$. Acoustic tags are suitable for detailed behavioral studies during shorter time periods (one to several months) and have been extensively used for understanding the migration and survival of juvenile salmonids during their transition from freshwater to marine waters (Chaput et al. 2019).

Currently, there are no general guidelines for the minimum fish size for marking with PIT-tags or acoustic transmitters, and research groups and animal welfare units around the world use different arguments and publications when defining guidelines for minimum fish and tag sizes. Guidelines such as the " $2 \%$ 
rule" (i.e. tag mass should not exceed $2 \%$ of the fish mass; Winter 1996) have been debated (Brown et al. 1999; Jepsen et al. 2005; Smircich and Kelly 2014), and we lack a systematic evaluation of tagging effects on growth and mortality to inform animal welfare units on appropriate tag size to fish size ratios. In large tagging programs, mass measurements are often so time consuming that it impedes animal welfare guidelines and only fish length is available to determine whether an individual meets the appropriate tagging thresholds. However, no evidence-based guidelines are currently available on appropriate tag:fish length ratio for tagging in juvenile salmonids.

Systematic reviews have been introduced in ecology as a way to assess general effects and develop guidelines for research and management based on the best available evidence, while overcoming variation among studies (Borenstein et al. 2010). Systematically evaluating candidate literature with standardized approaches for inclusion and exclusion eliminates some of the pitfalls of subjectivity of other review approaches (Haddaway et al. 2015). By extracting data from the publications identified in the systematic review, it is possible to conduct meta-analyses that can be used to analyze effects across publications. Given that tag effects on juvenile salmonids have been extensively explored for various species using internally implanted tags, this research question is suited to systematic review meta-analysis techniques, which can be used to develop guidelines for tagging juvenile salmonids. We opted to focus on experimental studies on impacts of PIT-tags or acoustic transmitters in controlled settings, which meant that survival and growth rates calculated from fish tagged and recaptured in nature were excluded. We did so because field studies are not consistently controlled, and survival is generally estimated using mark-recapture frameworks rather than direct observation. Candidate literature was appraised for the inclusion of survival or growth data on juvenile salmonids receiving internally implanted tags (either by surgery or injection with a syringe) into the body cavity. We included only studies of the closely related salmonine genera Oncorhynchus, Salmo, and Salvelinus because data on other species (e.g. grayling and whitefish) were very limited. Our main aim of the study was to determine whether a relationship between tag size and fish size on the survival and growth of these salmonid juveniles tagged with PIT-tags or acoustic transmitters was apparent across studies.

\section{Methods}

Systematic review

Candidate literature for the review was identified based on principles outlined for systematic reviews. We searched three literature sources (e.g. Falagas et al. 2008) using standard search strings created by finetuning search terms to maximize inclusion of potentially relevant publications (Appendix, Table A1). Literature searches were performed using the Scopus database and Clarivate Web of Science (January 2019). An additional search was performed using Google Scholar (January 2019), which can help to identify non-indexed grey literature published as university theses or technical reports (Haddaway et al. 2015). All results were initially screened by the title to determine whether they addressed juvenile salmonid tagging experiments. Full texts of the candidate literature were then downloaded for appraisal and metadata extraction. At this stage, reasons for excluding papers were noted for repeatability or covering methods other than PIT-tags and acoustic transmitters (Fig. 1). Metadata from candidate literature were extracted to investigate the relationships among fish species, fish length, tag size, and fish fate (survival and growth) while also considering potential contributing effects from other variables (e.g. temperature, tank size, wound closure, etc.).

The studies included in this review varied largely in terms of group sizes (ranging from 1 to 294,795) and fish weights (ranging from 0.61 to $773 \mathrm{~g}$ ). The design of the studies varied widely as well. Some publications contained one identifiable control group (i.e. untagged fish) and one treatment group (i.e. tagged fish). Others contained multiple control groups and multiple sham (i.e. fish that received surgery but no tag) and/or treatment groups. Controls may or may not have been in the same tank as treated fish. This made data verification challenging because it was difficult to identify implausible values. Only studies using PITtags (implanted into the body cavity either by surgery or injection with a syringe) had sufficient data and consistency to be included in the meta-analyses. For studies of acoustic transmitters, only a descriptive 


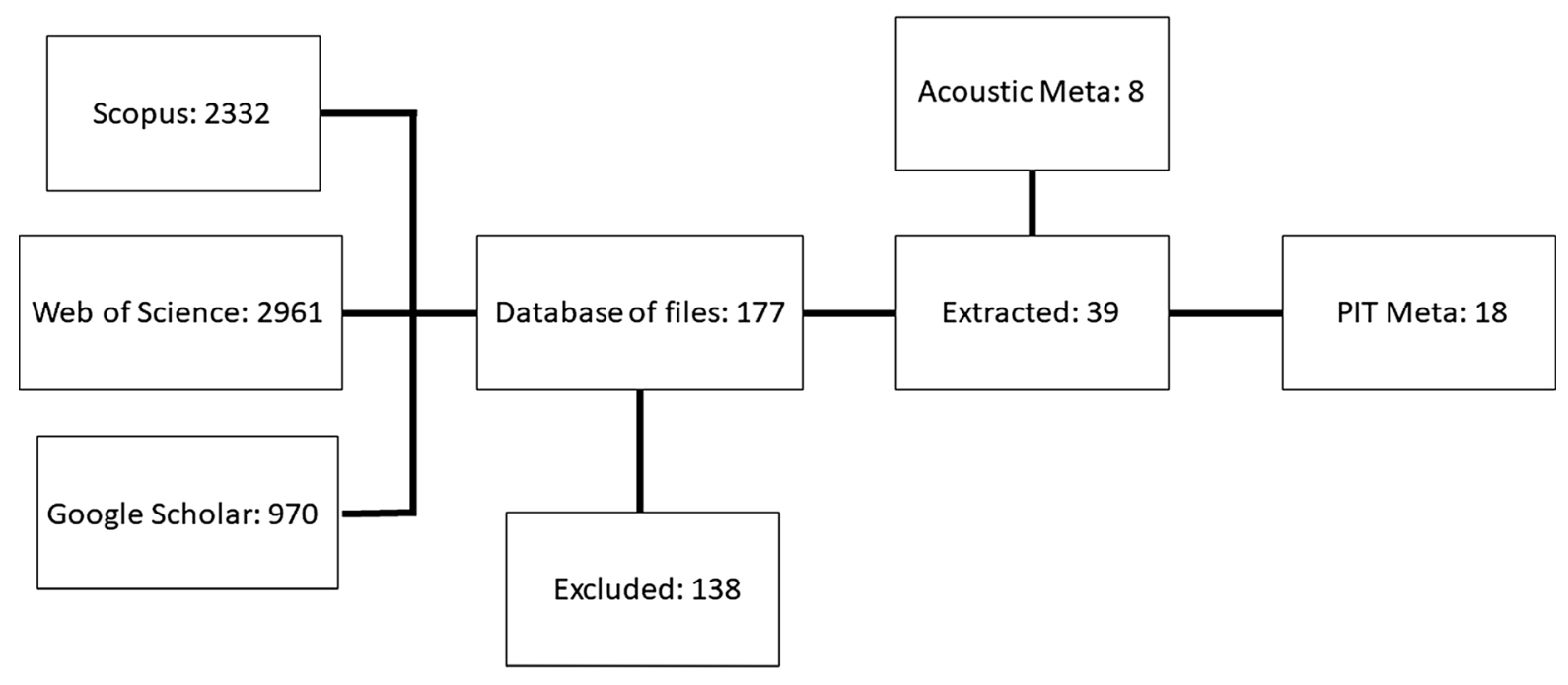

Fig. 1 Flow chart showing procedures of the systematic review of tagging effects on juvenile salmonids

analysis was performed due to a small number of studies. Data for other tag types were extracted but not evaluated because of small sample size. Data used in the meta-analyses of PIT-tag effects were limited according to the following criteria:

- Only data from publications that included at least one PIT-tagged group were used. If these studies included treatment groups using other tagging types, those treatment groups were excluded, but all control and sham groups retained.

- Studies that did not include at least one control group were excluded.

- Studies in which it was not possible to determine how follow-up was conducted were excluded.

- If a study recorded mortality on a daily or frequent basis, a subset of time points was selected to avoid collinearity between observations.

- One study included more than 200,000 fish per group (the next largest group size was 300) and was excluded to avoid the meta-analysis being dominated by that study and because of concern about follow-up in such a large study.

Data analysis

\section{Effects of PIT-tags}

Metadata on survival and individual data on fish size and tag size were extracted from each publication at the different time points given in the publications with the objective of analyzing mortality and growth of PIT tagged salmonids. Either average mass (in g) and fork or total length were extracted from each fish group for each publication. To standardize, we used the conversion factor from www.fishbase.org to convert all length measurements to total length for the final analysis. Mortality was measured as the cumulative number of deaths across time, and growth was determined based on the change in average length and mass of individuals per day.

\section{Mortality}

A random effects logistic regression model was fit to the cumulative mortality data using all available time points at which mortality was reported. The model was fit using maximum likelihood estimation with adaptive quadrature (Dohoo et al. 2009). The outcome was a binomial variable with the initial number of fish in each group as the denominator. Fixed effects hypothesized to affect survival were ratio of tag length to fish length (tag:fish length ratio; 0 for controls), time (days from the start of study), and fish species. Length rather than mass ratio was used because length measurements are more readily used in PIT tagging studies. The effect of time was not linear so time was logtransformed and centered on day 14. Because the variable "tag:fish length ratio" was coded zero for control and sham groups and there was no evidence of 
any difference between these two types of controls, we could use the ratio variable both to quantify the impact of tag size and to contrast tagged with non-tagged fish. No lack of fit was detected from this modelling of the impact of tagging in any of our models. The effect of tag:fish length ratio was non-linear, so a range of power transformations were considered with the best fit (based on AIC) being observed for the combination of a linear and quadratic term. Interactions between the two ratio terms (linear and quadratic) and time were evaluated.

We included the random effects of publication, fish group, and time point at which a measurement was made. Random slopes for time (i.e. a trend model) were investigated to allow for declining correlations between time points that were further apart. Convergence was not achieved with this random slope added, and few of the publications had multiple time points, so this was not considered further. Random slopes for the ratio terms were considered to allow for variation in ratio effects among publications (i.e. a random effects meta-analysis). Once again, the data were inadequate to support a model of this complexity. The final model included fixed effects for time posttagging, tag:fish length ratio (linear and quadratic terms) and two-way interactions between the two ratio terms and time, along with random effects for publication, group, and time point. Diagnostic procedures that evaluated normality, heterogeneity of variance, and outliers at appropriate levels were computed and evaluated using residual plots. Models were fit using standard procedures for multilevel, grouped binomial data in Stata 16.

In order to examine the possibility of variation in tag:fish length ratio effects among publications, a simpler model that contained only the time and tag:fish length ratio squared $\left(\right.$ ratio $^{2}$ ) fixed effects along with random effects for group and time points were fit to the data from each publication individually. From each of these analyses, the single ratio effect and its standard error were extracted, and these extracted results used in a standard random effects meta-analysis.

Two additional analyses were carried out. First, the effects of the interaction between time and tag:fish length ratio were explored by generating a plot of estimates of the effect of tag:fish length ratio at three different time points (7, 14 and 21 days). Secondly, we hypothesized that tagging effects would be higher if the overall mortality in the study was higher and therefore explored the effect of baseline risk (i.e. the survival in the control group) on the effect of tag:fish length ratio by estimating the odds ratio (OR) for treatment (tagging) separately for each publication and plotting this OR against the risk of mortality in the control group.

\section{Growth}

A number of publications reported either weights of study fish or lengths. In order to maximize the amount of data available for analyses, mass data that were missing were imputed (using a three degree fractional polynomial model) from length values (if recorded) and vice versa. The relationship between the average mass of the group and average length was strong with the fractional polynomial having an $\mathrm{R}^{2}>0.999$. For measures of within-group standard deviations (SD), the relationship was not as strong, but still the fractional polynomial had an $\mathrm{R}^{2}>0.85$. The $\mathrm{SD}$ values were not used in the models directly but were used to estimate appropriate weights for the studies when pooling them (details below). The models were fit using maximum likelihood estimation with adaptive quadrature.

Linear mixed models were used to analyze daily weight gain (dwg) and daily length gain (dlg). From the SD values for weight and length at the last time point, we computed approximate standard errors for $\mathrm{dwg}$ and $\mathrm{dlg}$ as $\mathrm{SD} / \mathrm{sqrt}(\mathrm{N}) /$ time. These values were considered as the known precision of the dwg and dlg estimates, whereupon variability between studies and study groups was added in the model, similar to the methods described by Ishak et al. (2007) for repeated measures meta-analysis. The predictors in the model were tag:fish length ratio, species and initial size (dwg or dlg). All quantitative predictors were centered to facilitate convergence of the estimation. For the same reason, dwg and dlg were scaled by multiplication by 10; however, all estimates and predictions are shown on original scale. There was no indication that the effect of ratio on dwg or dlg was non-linear, so it was included as a linear term. The models were fit by the gllamm module in Stata 16 using maximum likelihood estimation with adaptive quadrature. 


\section{Effects of acoustic transmitters}

A small number of publications $(n=8)$ reported results on tag effects when using acoustic transmitters. Attempts to fit a random effects meta-analysis produced unstable and illogical results so for each of these publications, the average mortality (total and daily) across fish groups within a treatment class (control, sham, treatment) was computed. The difference within each publication between the treatment and sham groups (if present) and control groups was computed and summarized.

The significance threshold was set to $P<0.05$ for all tests with the exception of the tag:fish length ratio $\times$ initial weight interaction term in the model for mass gain, which was retained at $P=0.053$.

\section{Results}

PIT tagging data

We extracted data from 18 publications, which yielded 206 time points from 165 groups of tagged fish (Table 1). The majority of groups $(\mathrm{N}=165)$ only had one measurement at a final time point when the number of mortalities was counted. The remaining 41 groups had measurements at two to five timepoints (Table 1). The extracted variables from the studies that ultimately played some role in the meta-analyses of the effects of PIT tagging on survival and growth are given in Table 2 .

\section{Mortality}

The final model for the effect of tag:fish length ratio on cumulative mortality (Table 3) was based on 199 observations from 158 fish groups within 18 unique publications. Tag:fish length ratio and tag:fish length ratio squared $\left(\right.$ ratio $^{2}$ ) were significant predictors of cumulative mortality and had significant interactions with time, suggesting that mortality responded nonlinearly to different fish:tag length ratios across time. Time was an important predictor on its own, which is intuitive given that the outcome was cumulative mortality, which can only increase with time. Within the publications, there was some variation among fish groups (after removing the effects of tag:fish length ratio and time), but little variation in mortality between time points within a group (see estimates of variance components in Table 3). This last observation was due to the limited number of groups that had multiple time points. Given that tag:fish length ratio appears in the model in four terms (linear and quadratic main effects and two interaction terms), the results were also evaluated graphically to visualize the effect of tag:fish length ratio (Fig. 2). The strong interaction between tag:fish length ratio squared and time suggests that the impact of tag:fish length ratio on mortality dropped off substantially over time, and was primarily high during a period shortly after tagging.

Random slopes could not be incorporated into the full model (Table 4) so an alternative approach was used based on estimating the effect of tag:fish length ratio squared in simpler models using data from each publication individually. Of the 18 publications, three were excluded for having no mortality and an additional five were excluded for producing extreme estimates with vary large SEs so they carried virtually no weight in the meta-analysis. This left 10 independent estimates of the effect of tag:fish length ratio squared. A meta-analysis of these estimates showed significant heterogeneity $(P=0.0016)$; of the ten estimates, one was negative but not significant, six were positive but not significant and three were positive and significant (Fig. 3). This suggests that, although there was variation among studies, the majority of the evidence pointed towards increased mortality as tag:fish length ratio increased.

There was no substantial difference in the modeled cumulative mortality estimate whether we estimated the effect of tag:fish length ratio at 7, 14 or 21 days post tagging (Fig. 4). The plot of OR for treatment effect vs baseline risk did not show any apparent effect of baseline risk on the effect of tag:fish length ratio.

\section{Growth}

Mean weights were imputed from mean lengths for 13 observations, whereas lengths were imputed from weights for 24 observations. Similarly, the standard deviation of weights ( $\mathrm{SD}$ (weight)) were imputed from $\mathrm{SD}$ (length) for 24 observations. There were no observations for which $\mathrm{SD}$ (length) was imputed from $\mathrm{SD}$ (weight).

In the final model for the effect of tag:fish length ratio on daily mass gain (Table 5), both tag:fish length ratio and the interaction term between the ratio and 
Table 1 List of 18 publications of which data were used in the meta-analysis to assess the effects of PIT-tagging on mortality and growth of juvenile salmonids

\begin{tabular}{|c|c|c|c|c|c|c|c|}
\hline \multirow[t]{2}{*}{ Author } & \multirow[t]{2}{*}{ Species } & \multirow{2}{*}{$\begin{array}{l}\text { Publication } \\
\text { year }\end{array}$} & \multirow{2}{*}{$\begin{array}{l}\text { Maximum } \\
\text { follow-up } \\
\text { time (days) }\end{array}$} & \multirow{2}{*}{$\begin{array}{l}\text { Average } \\
\text { ratio } \\
\text { value }^{b}\end{array}$} & \multicolumn{3}{|c|}{ Average cumulative mortality ${ }^{\mathrm{a}}$} \\
\hline & & & & & Controls & Sham & $\begin{array}{l}\text { Treated } \\
\text { (tagged) }\end{array}$ \\
\hline Acolas et al. & ST & 2007 & 26 & 0.22 & 0.04 & & 0.21 \\
\hline Ammann et al. & OT & 2013 & 221 & 0.07 & & 0.21 & 0.11 \\
\hline Bateman and Gresswell & $\mathrm{OM}$ & 2006 & 30 & 0.28 & 0 & 0 & 0.14 \\
\hline Bryson et al. & OT & 2013 & 14 & 0.1 & 0 & & 0 \\
\hline Huusko et al. & SS & 2014 & 33 & 0.11 & 0 & & 0 \\
\hline Lacroix et al. & SS & 2004 & 316 & 0.21 & 0.19 & 0 & 0.4 \\
\hline Larsen et al. & SS & 2013 & 35 & 0.35 & 0 & 0 & 0.05 \\
\hline Liss et al. & OT & 2016 & 90 & 0.18 & 0.03 & & 0.04 \\
\hline O'Donnell and Letcher & SF & 2017 & 64 & 0.21 & 0 & & 0 \\
\hline Ostrand et al. & $\mathrm{OK}, \mathrm{OM}, \mathrm{OC}, \mathrm{SC}$ & 2011 & 183 & 0.16 & 0.06 & & 0.04 \\
\hline Prentice et al. & OT, OM & 1990 & 570 & 0.18 & 0.08 & & 0.03 \\
\hline Prentice et al. & OT, ON & 1993 & 579 & 0.18 & 0.12 & 0.31 & 0.13 \\
\hline Prentice and Park & OK, OT & 1984 & 102 & 0.05 & 0.2 & 0.1 & 0.2 \\
\hline Richard et al. & ST & 2013 & 60 & 0.23 & 0.06 & & 0.13 \\
\hline Sigourney et al. & SS & 2005 & 247 & 0.18 & 0.04 & & 0.18 \\
\hline Tiffan et al. & OT & 2015 & 28 & 0.21 & 0 & & 0.01 \\
\hline Welch et al. & $\mathrm{OM}$ & 2007 & 203 & 0.11 & & & 0 \\
\hline Woodley et al. & OT, OM & 2011 & 30 & 0.1 & 0.61 & & 0.66 \\
\hline
\end{tabular}

Species codes: $\mathrm{ST}=$ Salmo trutta, OT = Oncorhynchus tshawytscha, OM = Oncorhynchus mykiss, SS = Salmo salar, $\mathrm{SF}=$ Salvelinus fontinalis,$\quad \mathrm{OK}=$ Oncorhynchus kisutch,$\quad \mathrm{OC}=$ Oncorhynchus clarkii,$\quad \mathrm{SC}=$ Salvelinus confluentus, $\mathrm{ON}=$ Oncorhynchus nerka

${ }^{a}$ Cumulative mortality measured at the end of the study follow-up period

${ }^{b}$ Average ratio value of PIT-tags in the treated groups in the publication

initial mass were borderline significant (combined $P$ value was 0.046 ). However, the dominant factor affecting daily mass gain was the initial starting mass of the fish. Larger fish had much higher daily mass gains. Tagging resulted in approximately a $10 \%$ to $20 \%$ reduction in daily mass gain across the time periods studied in these publications, with the larger effects observed for $23 \mathrm{~mm}$ tags (Table 6). Predictions were only generated for fish between 80 and $120 \mathrm{~mm}$ because the model had poor predictive ability for fish outside this range. In the final model for the effect of tag:fish length ratio on daily length gain (Table 7), only ratio was a significant predictor. Tagging resulted in a $4 \%$ to $13 \%$ reduction in daily length gain over the time periods studied in these publications (Table 8).
Acoustic tagging data

A total of 37 fish groups (13 control, 6 sham and 18 treatment) in the eight publications reported results from trials involving acoustic transmitters. The average difference between the mean (within publication) total mortality of the treatment and sham groups was 0.07 ( $\mathrm{SE}=0.11)$ and between treated and control groups was 0.02 ( $\mathrm{SE}=0.12$ ). Similarly, negligible differences were observed in daily mortality. Differences in mortality among control, sham-operated and fish tagged with acoustic transmitters were not statistically significant for either total $(P=0.83)$ or daily $(P=0.78)$ mortality. 
Table 2 Variables extracted from the literature review that ultimately played some role in the meta-analyses of the effects of PIT tagging on survival and growth

\begin{tabular}{|c|c|c|}
\hline & Name & Description \\
\hline \multicolumn{3}{|l|}{ Extracted variables } \\
\hline Publication & publ & A combination of author and publication year \\
\hline Group & id & $\begin{array}{l}\text { An identifiable group of fish within a publication } \\
\text { There may have been multiple control and/or } \\
\text { treatment groups within a publication }\end{array}$ \\
\hline Time & time & $\begin{array}{l}\text { Time points at which outcome } \\
\text { variable(s) (mortality, weight, length) were } \\
\text { recorded }\end{array}$ \\
\hline Treatment & $\mathrm{tx}$ & 3 categories: control, sham and treated \\
\hline Tag type & tx1 & $\begin{array}{l}17 \text { different types of tags/markings including PIT } \\
\text { tags, acoustic tags and many others }\end{array}$ \\
\hline Tag length & tag_lg & Length of tag (if relevant) \\
\hline Initial number of fish in group & fish0 & Range from 1 to 294,795 \\
\hline Initial average mass of fish & avg_wt0 & Range from 0.61 to $773 \mathrm{~g}$ \\
\hline Initial SD of mass of fish & sd_wt0 & Range from 0.01 to $265 \mathrm{~g}$ \\
\hline Initial average length of fish & avg_lg0 & Range from 14.9 to $450 \mathrm{~mm}$ \\
\hline Initial SD of length of fish & sd_lg0 & Range from 0 to $322.8 \mathrm{~mm}$ \\
\hline Fish alive at time $=\mathrm{t}$ & fish & \\
\hline Average mass at time $=\mathrm{t}$ & avg_wt & \\
\hline SD of mass at time $=\mathrm{t}$ & sd_wt & \\
\hline Average length at time $=\mathrm{t}$ & avg_lg & \\
\hline $\mathrm{SD}$ of length at time $=\mathrm{t}$ & sd_lg & \\
\hline Species & species & $\begin{array}{l}13 \text { species identified, later recoded into: } \\
\text { Oncorhynchus, Salmo and Salvelinus }\end{array}$ \\
\hline \multicolumn{3}{|l|}{ Computed variables } \\
\hline Cumulative mortality at time $=\mathrm{t}$ & cum_died & fish-fish0 \\
\hline Ratio of length of PIT tag to initial length of fish & ratio & tag_lg/avg_lg0 \\
\hline Ratio squared (and other power terms) & ratio $^{2}$ & ratio $^{2}$ (or other power terms) \\
\hline Daily mass gain & dwg_ln & (avg_wt - avg_wt0)/time, then log transformed \\
\hline Daily length gain & $\mathrm{dlg}$ & $($ avg_lg - avg_lg0)/time \\
\hline
\end{tabular}

Table 3 Mortality results of the meta-analysis

\begin{tabular}{lrccrr}
\hline & Coefficient & Standard error & $P$ value & 95\% confidence interval \\
\hline Ratio & -14.41 & 6.75 & 0.03 & -27.64 & -1.19 \\
Time & 2.04 & 0.17 & 0.00 & 1.71 & 2.37 \\
Ratio $\times$ time & 4.77 & 2.94 & 0.11 & -0.99 & 10.53 \\
Ratio $^{2}$ & 125.26 & 26.26 & 0.00 & 73.79 & 176.73 \\
Ratio $^{2} \times$ time & -41.88 & 10.99 & 0.00 & -63.42 & -20.35 \\
Intercept & -7.52 & 0.71 & 0.00 & -8.90 & -6.13 \\
Variance terms & & & & & \\
Publication & 6.20 & 2.49 & & 2.82 & 13.62 \\
Fish group & 0.57 & 0.18 & & 0.31 & 1.04 \\
Time point & 0.14 & 0.05 & & 0.07 & 0.29 \\
\hline
\end{tabular}




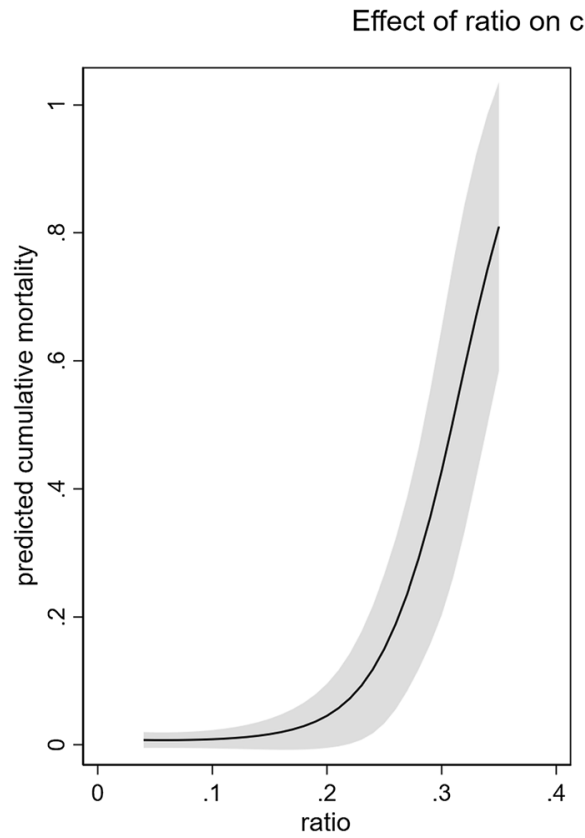

Fig. 2 A plot of the effect of fish:tag length ratio and its 95\% confidence interval on cumulative mortality at day 14 . The left panel shows the effect of ratio across the full range of observed

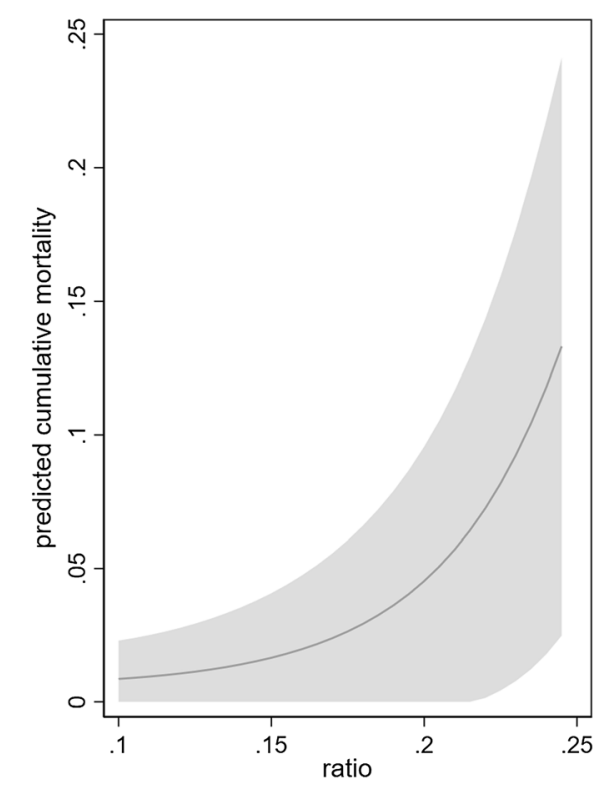

values of ratio while the right panel shows, in greater detail, the effect in the critical range where mortality starts to rise

Table 4 Predicted cumulative mortality at 14 days post-tagging for two PIT tag sizes and at three fish lengths (the 25th, 50th and 75th percentiles of lengths observed in publications used in this meta-analysis)

\begin{tabular}{lllllc}
\hline Tag size $(\mathrm{mm})$ & Fish length $(\mathrm{mm})$ & Ratio & Predicted mortality & \multicolumn{2}{c}{$95 \%$ confidence interval } \\
\hline 0 & Any & 0 & 0.01 & 0.00 & 0.03 \\
12 & 70 & 0.17 & 0.02 & 0.00 & 0.06 \\
12 & 83 & 0.14 & 0.01 & 0.00 & 0.04 \\
12 & 130 & 0.09 & 0.01 & 0.00 & 0.02 \\
23 & 70 & 0.33 & 0.67 & 0.42 & 0.92 \\
23 & 83 & 0.28 & 0.29 & 0.12 & 0.46 \\
23 & 130 & 0.18 & 0.03 & 0.00 & 0.07 \\
\hline
\end{tabular}

\section{Discussion}

Handling and tagging is stressful for fish and the effects can manifest in the individual's physiology, behaviour, and fate (tertiary stress response). Tagging effects studies evaluate the magnitude of impacts for scientific assessment of the results ascertained from studies applying the methodology and to make informed animal welfare decisions. The relationship between tag size and body size is the subject of multiple review papers not only for fish, but also for mammals and birds (e.g. Naef-Daenzer et al. 2001;
Walker et al. 2012). However, this is the first metaanalysis that has explicitly extracted data from multiple experimental studies to quantify the effect of the tag:fish length ratio on tagging-related mortality in juvenile salmonids. We found that mortality increased curvilinearly with the tag:fish length ratio in PIT tagging studies, indicating a non-linear increase in mortality meaning that mortality risk is rapidly enhanced as smaller fish or larger tag sizes are used. On the other hand, the tag:fish length ratio effect on daily length or mass gain measurements was linear. Our meta-analysis suggests that the tag:fish length 


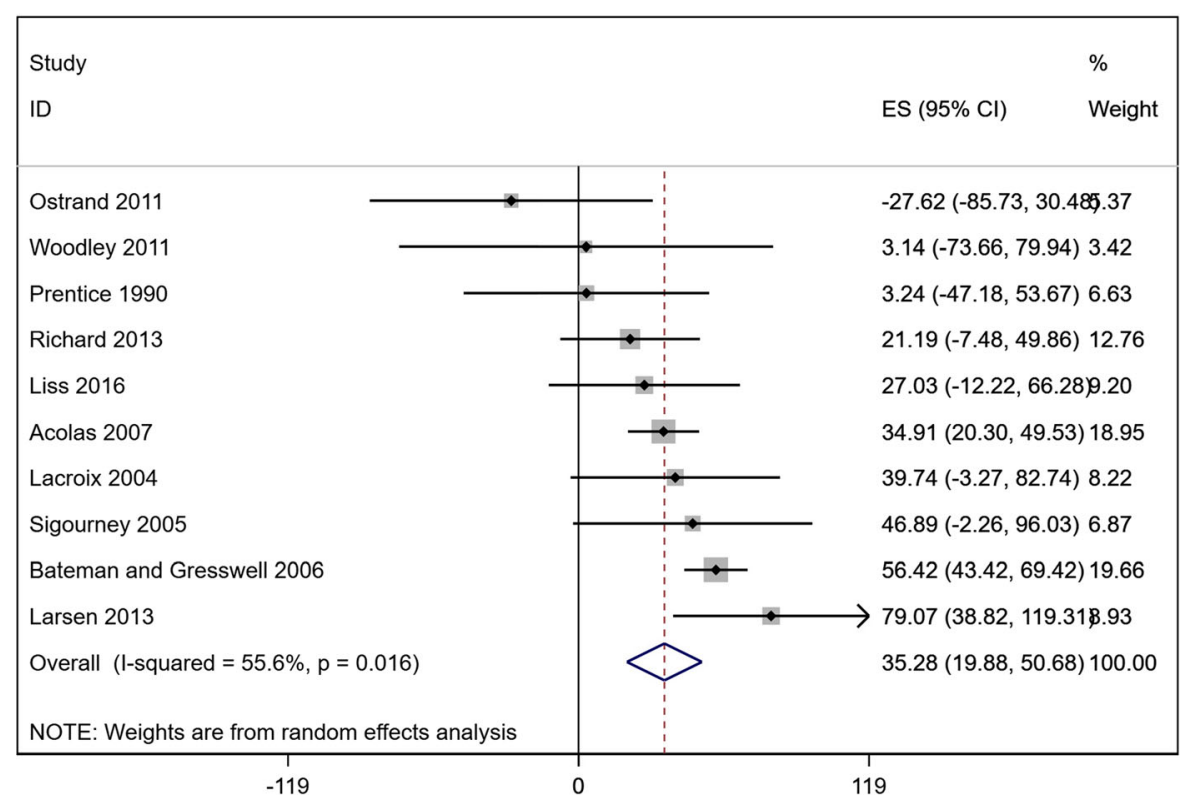

Fig. 3 A forest plot of the individual estimates of the effect of ratio (squared) derived from 10 publications

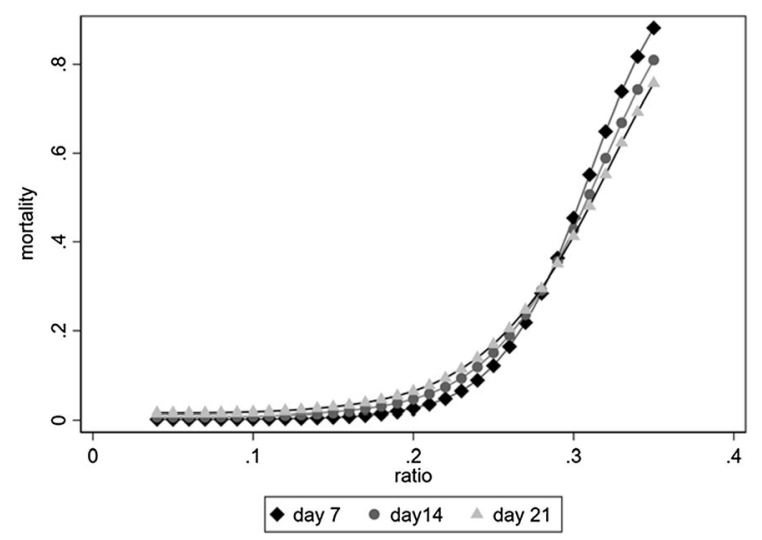

Fig. 4 A plot showing the marginal effects of fish:tag length ratio (linear and quadratic terms) on cumulative mortality if the time of assessment of the ratio effects is changed from 14 days (original analysis) to either 7 or 21 days ratio is an important parameter to inform PIT tagging programs and welfare committees tasked with defining robust and precautionary limits to experiments using fish.

Mortality is an extreme response to tagging, overlying physiological impacts of the tagging on organ function, blood circulation, immune responses, and buoyancy control. Allocation of resources by fish to compensate for physiological impacts of tagging can negatively impact growth (length and/or weight) rate of an individual (i.e. tertiary stress response; Wendelaar Bonga 1997). We observed a linear relationship with reduced growth (both mass and length) as the tag:fish length ratio increased. It was not possible to ascertain why growth was affected in the present meta-analysis. However possible causes of

Table 5 Factors affecting daily mass gain in PIT-tagged fish

\begin{tabular}{lrlcccc}
\hline & \multicolumn{1}{c}{ Coef. } & Standard error & $\mathrm{Z}$ & $P>\mathrm{z}$ & \multicolumn{2}{c}{$95 \%$ confidence interval } \\
\hline Initial weight & 0.032 & 0.007 & 4.32 & 0 & 0.017 & 0.046 \\
Ratio & -0.422 & 0.254 & -1.66 & 0.097 & -0.92 & 0.076 \\
Ratio $\times$ initial weight & -0.081 & 0.042 & -1.94 & 0.053 & -0.163 & 0.001 \\
Intercept & 0.839 & 0.155 & 5.41 & 0 & 0.535 & 1.143 \\
\hline
\end{tabular}

Daily mass gain was computed as the average over the entire follow-up period. The outcome was daily mass gain $\times 10$ and all predictors were centered. The combined significance of ratio and its interaction with initial mass was $P=0.046$ 
Table 6 Predicted effects of tagging with 12 or 23 mm PIT tags on daily mass gain in fish of three different initial lengths

\begin{tabular}{|c|c|c|c|c|c|c|}
\hline $\begin{array}{l}\text { Tag size } \\
(\mathrm{mm})\end{array}$ & $\begin{array}{l}\text { Fish length } \\
(\mathrm{mm})\end{array}$ & Ratio & $\begin{array}{l}\text { Estimate } \\
\text { weight }^{\mathrm{a}}\end{array}$ & $\begin{array}{l}\text { Predicted daily } \\
\text { mass gain (control) }\end{array}$ & $\begin{array}{l}\text { Predicted daily } \\
\text { mass gain (tagged) }\end{array}$ & $\begin{array}{l}\text { Relative } \\
\text { proportion }\end{array}$ \\
\hline 12 & 120 & 0.1 & 16 & 0.13 & 0.12 & 0.91 \\
\hline 12 & 80 & 0.15 & 9 & 0.10 & 0.09 & 0.90 \\
\hline 12 & 40 & 0.3 & 1.2 & 0.07 & 0.07 & 0.99 \\
\hline 23 & 120 & 0.19 & 16 & 0.13 & 0.11 & 0.82 \\
\hline 23 & 80 & 0.29 & 9 & 0.10 & 0.08 & 0.81 \\
\hline
\end{tabular}

${ }^{\mathrm{a}}$ The estimated weight was the expected weigh of a fish of the given length (e.g. $120 \mathrm{~mm}$ ) based on the observed relationship between fish length and fish weight

Table 7 Factors affecting daily length gain in PIT-tagged fish

\begin{tabular}{lllllll}
\hline & Coef. & SE & $\mathrm{Z}$ & $P$ value & $95 \%$ confidence interval \\
\hline Ratio & -1.554 & 0.706 & -2.2 & 0.0028 & -2.939 & -0.169 \\
Intercept & 3.349 & 0.562 & 5.96 & 0 & 2.247 & 4.451 \\
\hline
\end{tabular}

Daily length gain was computed as the average over the entire follow-up period

Table 8 Predicted effects of tagging with 12 or $23 \mathrm{~mm}$ PIT tags on daily length gain in fish of three different initial lengths

\begin{tabular}{llllll}
\hline $\begin{array}{l}\text { Tag size } \\
(\mathrm{mm})\end{array}$ & $\begin{array}{l}\text { Fish length } \\
(\mathrm{mm})\end{array}$ & Ratio & $\begin{array}{l}\text { Predicted daily } \\
\text { length gain (control) }\end{array}$ & $\begin{array}{l}\text { Predicted daily } \\
\text { length gain (tagged) }\end{array}$ & $\begin{array}{l}\text { Relative } \\
\text { proportion }\end{array}$ \\
\hline 12 & 120 & 0.1 & 0.35 & 0.34 & 0.96 \\
12 & 80 & 0.15 & 0.35 & 0.33 & 0.93 \\
12 & 40 & 0.3 & 0.35 & 0.31 & 0.87 \\
23 & 120 & 0.19 & 0.35 & 0.32 & 0.92 \\
23 & 80 & 0.29 & 0.35 & 0.31 & 0.87 \\
\hline
\end{tabular}

decreased growth may include greater energetic costs of maintaining buoyancy due to negatively buoyant tags, physiological stress responses, decreased body cavity volume affecting feeding rate, reduced competitive ability on foraging success, behavioural responses (e.g. decreased feeding activity due to the burden of the tag or increased energy expenditure related to increased activity), and stress responses (Fried et al. 1976; Wendelaar Bonga 1997; Wright et al. 2019). In addition, it should be noted that the measurements we extracted for meta-analysis were averaged across experimental replicates and growth responses may in fact be larger in some fish because effects may be masked in averages if individuals within the same tank are affected differently, for example as a consequence of metabolic rate or dominance hierarchy among individuals in a tank. Growth was also generally measured over a relatively short period. If measured over longer time-intervals, individuals may be able to compensate for reduced growth shortly after tagging (e.g. Ostrand et al. 2011; Smircich and Kelly 2014). Such compensatory growth may, however, come with additional costs (e.g. immunity), affecting long-term survival (Metcalfe and Monaghan 2001).

There was no evidence of differences in tagging effects among species. We specifically identified studies on juvenile salmonines from the genera Oncorhynchus, Salmo, and Salvelinus for this metaanalysis, excluding other salmonids such as 
thymallines and coregonines. The salmonid species included in this study are species from temperate environments commonly tagged in association with their downstream migration to the ocean. Limiting our search to these species, and specifically to juvenile life stages, presumably influenced the extent to which we were likely to observe differences among species. Members of other, more distantly related species such as percids (e.g. Perca flavescens, P. fluviatilis) or cyprinids (e.g. Cyprinus carpio) may yield different results. We focused on relatively coarse measurements, mortality and growth, which may be less likely to reveal any species-specific differences. Finer scale measurements of growth trajectories, blood physiology, behaviour, buoyancy and other individual-based variables are needed to identify differences that may exist among species (Newby et al. 2007; Makiguchi and Kojima 2017). Nonetheless, we considered the effect of species in our models to account for potential differences, given our hypothesis that such differences may exist. It should also be pointed out that growth is a useful metric for assessing fish welfare in tagging studies, because a wide range of impacts of tagging will ultimately manifest as an impact on growth (as discussed in the paragraph above).

We hypothesized that tagging effects would be more extreme in situations when overall survival was poor because of synergistic effects of multiple stressors. When mortality of control group individuals is high due to, for example, stressful conditions such as poor water quality (i.e. pollution, acidification) or stressful water temperature (Kroglund et al. 2007), these effects may multiply the stress experienced by the treatment group. However, baseline survival had no influence on tagging effects, indicating that the tagging induced mortality was not higher under poorer survival conditions. It is important to note that these results do not necessarily extend to conditions in the wild, where fish may be confronted by predators or disease, which may exacerbate tagging effects in a differently than in tank studies. Multiple examples indicate that fish in substandard condition will be more likely be eaten by predators (Mesa et al. 1994), and even though mortality is not significantly increased in a laboratory setting, the impact of tagging may still materialize in the field. Studies that have attempted to circumvent the challenge of studying tagging effects in situ have usually done so by double tagging, where miniature tags that are assumed to have little effect function as the control, or by making a comparison between groups with large and small tags (e.g. Knudsen et al. 2009). However, such designs assume that there are no synergistic effects of the second tag.

There were insufficient data from acoustic tagging studies to carry out a quantitative meta-analysis. However, a comparison of average mortality rates across treatment groups and studies was performed, and the mortality did not significantly differ between the tagged groups and the sham or control fish. Acoustic tags usually have the same cylindrical shape as PIT-tags, but they are larger in diameter and mass, and usually also in length, although the length of the largest PIT-tags is comparable to the length of many acoustic transmitters (Rub et al. 2014). Like PIT-tags, acoustic transmitters are usually surgically implanted in the body cavity. However, due to their larger size, the incision required for implanting acoustic tags is larger than for PIT-tags, and is generally closed by using 1-3 sutures, which may result in greater impacts on tagged individuals. Indeed, acoustic transmitters may be more frequently expelled, may cause organ and tissue necrosis, and may result in more complications with healing of the incision (Jepsen et al. 2008; Rub et al. 2014). However, results of the present metaanalysis indicated that neither acoustic tags nor PITtags were associated with substantial mortality resulting from tagging effects, if the tag is appropriately small. Caution is warranted for this conclusion because the inability to conduct a meta-analysis on acoustic tags means advice on tag size using acoustic tags should be precautionary.

Several recommendations have been made related to the tagging size restriction in juvenile fish. For example, Peterson et al. (1994) recommended the use of $11 \mathrm{~mm}$ tags in coho salmon $>65 \mathrm{~mm}$ (FL) (equivalent to a ratio of $\geq 0.17$ ). Larsen et al. (2013) concluded that intracoelomic implantation of $23 \mathrm{~mm}$ PIT-tags is appropriate for Atlantic salmon $>99 \mathrm{~mm}$ FL (max. acceptable ratio $=0.23$ ) and that $32 \mathrm{~mm}$ PIT-tags should not be used for marking Atlantic salmon $80-135 \mathrm{~mm}$ FL (max. acceptable ratio $=0.24)$. Acolas et al. (2007) assessed survival, growth and tag retention following PIT-tagging of juvenile brown trout in a 27-day laboratory experiment, and concluded that brown trout $\geq 57 \mathrm{~mm}$ FL can be tagged by injecting $11.5 \mathrm{~mm}$ PIT-tags (max. acceptable ratio $=0.20$ ) into the peritoneal cavity with negligible effects on survival and growth, however, 
the tag loss rate was very high (20\%). Ostrand et al. (2011) conducted a four-month laboratory experiment with minimal effects on long-term survival, growth, and physiology in salmonids with a fork length of $>120 \mathrm{~mm}$ and $>20 \mathrm{~g}$, using either 12 or $23 \mathrm{~mm}$ tags. Tiffan et al. (2015) investigated effects of 8-, 9-, and $12 \mathrm{~mm}$ PIT-tags on growth, survival and tag-retention of chinook salmon juveniles in three size classes. The main conclusion from their study was that biologically relevant effects on growth and survival were negligible using (1) tags up to $9 \mathrm{~mm}$ for $40-49 \mathrm{~mm}$ fish (maximum acceptable ratio $=0.23$ ) and (2) tags up to $12 \mathrm{~mm}$ for 50-69 mm fish (maximum acceptable ratio $=0.24$ ), over the first month post-tagging (Tiffan et al. 2015). All these recommendations were made on the basis of single studies whereas our meta-analysis provides a tool that can be used to predict taggingrelated mortality of juvenile salmonids based on the fish sizes and tag lengths selected. In doing so, the predicted level of mortality can be used to guide the research and make appropriate decisions related to fish welfare and experimental design. Because the effect of species was not significant, the relationship seems to be valid across juvenile salmonid species within the genera Oncorhynchus, Salmo, and Salvelinus. In studies that are highly sensitive to fish mortality, the tool can be applied to identify highly conservative tag lengths relative to the fish sizes available.

Animal care, ethics, use, and welfare committees around the world may point to tag:fish length ratios to ensure that the animal welfare standards are upheld in scientific research. Further, most tagging-based studies of fish ecology rely on the assumption that tagged individuals behave similarly to un-tagged conspecifics (Cooke et al. 2011), which will not be met if tagging induces changes in growth and mortality rates. It must be emphasized that the effect of setting a lower threshold unnecessarily high can also have animal welfare implications. For example, if the size limits are too strict, researchers may switch to smaller and less effective tags, which will require study designs in which more individuals are tagged to attain equivalent power. This goes against the principle of reduction in animal welfare ethics (Russell and Burch 1959) and is an important trade-off to consider when designing research and surveillance programs. Additionally, if size limits are too restrictive, researchers are left with using experimental animals that are not representative of the population, biasing the results in the short term and leading to unnecessary repetition of studies in the long term. Consequently, resolving the debate around allowable minimum size thresholds for marking salmon with PIT-tags is important for fish welfare and the future of salmon research programs.

Another word of caution is that our studies have focused on the ratio of the PIT tag to the length of the fish body. This was mainly motivated by the observation that length measurements are routinely collected during tagging studies, whereas mass is recorded less frequently to minimize animal handling during tagging because obtaining accurate measurements of mass is challenging and takes longer than measuring length. For tagging studies using larger diameter tags (e.g. acoustic or radio tags), tag volume or tag diameter may become an important variable for assessing tagging-related effects on growth and mortality, which could be evaluated in a future effort should sufficient sample size permit application of the methods used here for assessing PIT tagging effects. However, the body cavity volume where the tag is placed is related to the length of the fish, i.e. it is proportional to the cube of fish length and tag. Consequently, the ratio of PIT tag length to fish body length may still be a useful indicator of tagging effects but caution should be applied when extrapolating our results to studies using different tag types and size ranges.

Conclusion and suggestion for threshold limits for tagging

The results of our meta-analysis provide an estimate of the effects of the tag:fish length ratio on both mortality and growth parameters in juvenile salmonids. We believe this information can assist researchers, managers, and welfare agencies striving to use the best possible evidence to make informed decisions regarding fish tagging. We encourage further research on tag effects and note that in future investigations, a clear description of the study design along with measures of initial fish numbers and size (mass and length), tag dimensions and regular measurements of mortality, mass and length (preferably over at least 60 days) should be published. Our literature screening revealed knowledge gaps related to the effects of water temperature on survival following tagging. Consequently, providing ancillary measures such as water temperature, tank dimensions, and fish density would 
be useful in understanding heterogeneity among studies. More research is also needed to develop specific recommendations for other tag types for which we had less information than for PIT tags.

All electronic tagging should strive to achieve 0\% tagging mortality by implementing best practices for tagging and use of appropriate tag sizes. In practice, attaining $0 \%$ tagging mortality may not always be realistic. We emphasize that the correct ratio depends on the level of acceptable mortality, which is up to the investigator to decide. There are three points of interest on the plots (see Fig. 1a, b), the point where the curve rises beyond 0 indicating non-zero mortality, the point where the confidence interval departs from zero, indicating more certain non-zero mortality, and the increase beyond 5\% mortality. At the 5\% mortality threshold, 0 is still within the confidence interval and represents an intermediate between the curve and the confidence interval surpassing zero; given the conservative nature of this, we suggest that the $17.5 \%$ ratio at which expected mortality is approximately $5 \%$ with a lower bound of $0 \%$ is an acceptable rule of thumb. This would equate to a minimum size threshold of $131 \mathrm{~mm}$ for tagging salmonids with 23-mm PIT tags or $69 \mathrm{~mm}$ with 12-mm PIT tags.

Acknowledgements The initiation of this study was financed by the Norwegian Environmental Agency. Knut Wiik Vollset was financed by the Norwegian Research Council through the project SeaSalar (Project 280308), during the writing of the manuscript. This manuscript was result of a workshop where the following people participated but are not an author of the final manuscript: Abdullah Madhun, Bengt Finstad, Trond Einar Isaksen, Vidar Wennevik, Dag Atle Tuft, Rune Nilsen, Ørjan Karlsen, Jan G. Davidsen, Kjell Utne, Harald Sægrov, Per Tommy Fjeldheim and Danielle Frechette. Special thanks to Danielle Frechette for valuable input during the finalization of the manuscript. We would like to extend our gratitude to all these participants and their valuable input to the discussion.

Funding Open Access funding provided by NORCE Norwegian Research Centre AS.

Data availability Final extracted dataset is available here https://arkivering.nsd.no/ac1b0003-6ee4-101d-8170b00584bb010c\#.

Open Access This article is licensed under a Creative Commons Attribution 4.0 International License, which permits use, sharing, adaptation, distribution and reproduction in any medium or format, as long as you give appropriate credit to the original author(s) and the source, provide a link to the Creative Commons licence, and indicate if changes were made. The images or other third party material in this article are included in the article's Creative Commons licence, unless indicated otherwise in a credit line to the material. If material is not included in the article's Creative Commons licence and your intended use is not permitted by statutory regulation or exceeds the permitted use, you will need to obtain permission directly from the copyright holder. To view a copy of this licence, visit http://creativecommons.org/licenses/by/4.0/.

\section{References}

Aarestrup K, Lucas MC, Hansen JA (2003) Efficiency of a nature-like bypass channel for sea trout (Salmo trutta) ascending a small Danish stream studied by PIT telemetry. Ecol Freshw Fish 12(3):160-168

Acolas ML, Roussel JM, Lebel JM, Baglinière JL (2007) Laboratory experiment on survival, growth and tag retention following PIT injection into the body cavity of juvenile brown trout (Salmo trutta). Fish Res 86(2-3):280-284

Adams NS, Rondorf DW, Evans SD, Kelly JE (1998) Effects of surgically and gastrically implanted radio transmitters on growth and feeding behavior of juvenile Chinook salmon. Trans Am Fish Soc 127(1):128-136

Ammann AJ, Michel CJ, MacFarlane RB (2013) The effects of surgically implanted acoustic transmitters on laboratory growth, survival and tag retention in hatchery yearling Chinook salmon. Environ Biol Fishes 96(2-3):135-143

Bateman DS, Gresswell RE (2006) Survival and growth of age-0 steelhead after surgical implantation of $23-\mathrm{mm}$ passive integrated transponders. N Am J Fish Manag 26(3):545-550

Borenstein M, Hedges LV, Higgins JP, Rothstein HR (2010) A basic introduction to fixed-effect and random-effects models for meta-analysis. Res Synth Methods 1(2):97-111

Brown RS, Cooke SJ, Anderson WG, McKinley RS (1999) Evidence to challenge the "2\% rule" for biotelemetry. N Am J Fish Manag 19(3):867-871

Bryson AJ, Woodley CM, Karls RK, Hall KD, Weiland MA, Deng ZD et al (2013) Comparison of 180-degree and 90-degree needle rotation to reduce wound size in PITinjected juvenile Chinook salmon. Fish Res 143:201-204

Burnett NJ, Hinch SG, Donaldson MR, Furey NB, Patterson DA, Roscoe DW, Cooke SJ (2014) Alterations to dam-spill discharge influence sex-specific activity, behaviour and passage success of migrating adult sockeye salmon. Ecohydrology 7(4):1094-1104

Chaput G, Carr J, Daniels J, Tinker S, Jonsen I, Whoriskey F (2019) Atlantic salmon (Salmo salar) smolt and early postsmolt migration and survival inferred from multi-year and multi-stock acoustic telemetry studies in the Gulf of St. Lawrence, northwest Atlantic. ICES J Mar Sci 76(4):1107-1121

Cooke SJ, Hinch SG, Crossin GT, Patterson DA, English KK, Healey MC et al (2006) Mechanistic basis of individual mortality in Pacific salmon during spawning migrations. Ecology 87(6):1575-1586

Cooke SJ, Woodley CM, Eppard MB, Brown RS, Nielsen JL (2011) Advancing the surgical implantation of electronic tags in fish: a gap analysis and research agenda based on a 
review of trends in intracoelomic tagging effects studies. Rev Fish Biol Fish 21(1):127-151

Dohoo IR, Martin SW, Stryhn H (2009) Veterinary epidemiologic research, 2nd edn. VER Inc, New York, pp 594-596

Falagas ME, Pitsouni EI, Malietzis GA, Pappas G (2008) Comparison of PubMed, Scopus, Web of Science, and Google Scholar: strengths and weaknesses. FASEB J 22:338-342

Forseth T, Barlaup BT, Finstad B, Fiske P, Gjøsæter H, Falkegård $\mathrm{M}$ et al (2017) The major threats to Atlantic salmon in Norway. ICES J Mar Sci 74(6):1496-1513

Fried SM, McCleave JD, Stred KA (1976) Buoyancy compensation by Atlantic salmon (Salmo salar) smolts tagged internally with dummy telemetry transmitters. J Fish Res Board Can 33(6): 1377-1380

Gibbons WJ, Andrews KM (2004) PIT tagging: simple technology at its best. Bioscience 54(5):447-454

Haddaway NR, Woodcock P, Macura B, Collins A (2015) Making literature reviews more reliable through application of lessons from systematic reviews. Conserv Biol 29(6):1596-1605

Huusko R, Huusko A, Mäki-Petäys A, Orell P, Erkinaro J (2016) Effects of tagging on migration behaviour, survival and growth of hatchery-reared Atlantic salmon smolts. Fish Manag Ecol 23(5):367-375

Ishak KJ, Platt RW, Joseph L, Hanley JA, Caro JJ (2007) Metaanalysis of longitudinal studies. Clin Trials 4(5):525-539

Jepsen N, Schreck C, Clements S, Thorstad EB (2005) A brief discussion on the $2 \%$ tag/bodymass rule of thumb. In: Spedicato MT, Lembo G, Marmulla G (eds) Aquatic telemetry: advances and applications. FAO, Rome, pp 255-259

Jepsen N, Mikkelsen JS, Koed A (2008) Effects of tag and suture type on survival and growth of brown trout with surgically implanted telemetry tags in the wild. J Fish Biol 72(3):594-602

Jepsen N, Thorstad EB, Havn T, Lucas MC (2015) The use of external electronic tags on fish: an evaluation of tag retention and tagging effects. Anim Biotelem 3(1):49

Källo K, Baktoft H, Jepsen N, Aarestrup K (2020) Great cormorant (Phalacrocorax carbo sinensis) predation on juvenile down-migrating trout (Salmo trutta) in a lowland stream. ICES J Mar Sci 77:721-729

Knudsen CM, Johnston MV, Schroder SL, Bosch WJ, Fast DE, Strom CR (2009) Effects of passive integrated transponder tags on smolt-to-adult recruit survival, growth, and behavior of hatchery spring Chinook salmon. N Am J Fish Manag 29(3):658-669

Kroglund F, Rosseland BO, Teien HC, Salbu B, Kristensen T, Finstad B (2007) Water quality limits for Atlantic salmon (Salmo salar L.) exposed to short term reductions in $\mathrm{pH}$ and increased aluminum simulating episodes. Hydrol Earth Syst Sci Discuss 4(5):3317-3355

Lacroix GL, Knox D, McCurdy P (2004) Effects of implanted dummy acoustic transmitters on juvenile Atlantic salmon. Trans Am Fish Soc 133(1):211-220

Larsen MH, Thorn AN, Skov C, Aarestrup K (2013) Effects of passive integrated transponder tags on survival and growth of juvenile Atlantic salmon Salmo salar. Anim Biotelem 1(1):19
Liss SA, Brown RS, Deters KA, Walker RW, Deng ZD, Eppard MB et al (2016) Mortality, transmitter retention, growth, and wound healing in juvenile salmon injected with micro acoustic transmitters. Trans Am Fish Soc 145(5):1047-1058

Makiguchi Y, Kojima T (2017) Short term effects of relative tag size and surgical implantation on feeding behaviour, survival rate, plasma lactate and growth rate in juvenile to adult rainbow trout (Oncorhynchus mykiss). Fish Res $185: 54-61$

Markus HC (1933) The effects of tags upon fresh water fishes. Trans Am Fish Soc 63(1):319-325

Mesa MG, Poe TP, Gadomski DM, Petersen J (1994) Are all prey created equal? A review and synthesis of differential predation on prey in substandard condition. J Fish Biol 45:81-96

Metcalfe NB, Monaghan P (2001) Compensation for a bad start: grow now, pay later? Trends Ecol Evol 16(5):254-260

Naef-Daenzer B, Widmer F, Nuber M (2001) A test for effects of radio-tagging on survival and movements of small birds. Avian Sci 1(1):15-23

Newby NC, Binder TR, Stevens ED (2007) Passive integrated transponder (PIT) tagging did not negatively affect the short-term feeding behavior or swimming performance of juvenile rainbow trout. Trans Am Fish Soc 136(2):341-345

O’Donnell JM, Letcher BH (2017) Implanting 8-mm passive integrated transponder tags into small Brook Trout: effects on growth and survival in the laboratory. N Am J Fish Manag 37(3):605-611

Økland F, Erkinaro J, Moen K, Niemelä E, Fiske P, McKinley RS, Thorstad EB (2001) Return migration of Atlantic salmon in the River Tana: phases of migratory behaviour. J Fish Biol 59:862-874

Ostrand KG, Zydlewski GB, Gale WL, Zydlewski JD (2011) Long term retention, survival, growth, and physiological indicators of juvenile salmonids marked with passive integrated transponder tags. Am Fish Soc Symp 76:1-11

Pechacek LS (1956) The effects of tags on the rate of growth and condition of several species of cold-water fish in Wyoming. Prog Fish Cult 18(3):120-125

Peterson NP, Prentice EF, Quinn TP (1994) Comparison of sequential coded wire and passive integrated transponder tags for assessing overwinter growth and survival of juvenile coho salmon. N Am J Fish Manag 14(4):870-873

Prentice EF, Park DL (1984) A study to determine the biological feasibility of a new fish tagging system. Annu Rep Res 1983:84

Raby GD, Donaldson MR, Hinch SG, Patterson DA, Lotto AG, Robichaud D et al (2012) Validation of reflex indicators for measuring vitality and predicting the delayed mortality of wild coho salmon bycatch released from fishing gears. J Appl Ecol 49(1):90-98

Rasiulis AL, Festa-Bianchet M, Couturier S, Côté SD (2014) The effect of radio-collar masson survival of migratory caribou. J Wildl Manag 78(5):953-956

Richard A, O'Rourke J, Caudron A, Cattanéo F (2013) Effects of passive integrated transponder tagging methods on survival, tag retention and growth of age- 0 brown trout. Fish Res 145:37-42

Richard A, Bernatchez L, Valiquette E, Dionne M (2014) Telemetry reveals how catch and release affects 
prespawning migration in Atlantic salmon (Salmo salar). Can J Fish Aquat Sci 71(11):1730-1739

Roussel JM, Haro A, Cunjak RA (2000) Field test of a new method for tracking small fishes in shallow rivers using passive integrated transponder (PIT) technology. Can J Fish Aquat Sci 57(7):1326-1329

Rub AMW, Jepsen N, Liedtke TL, Moser ML, Weber EPS (2014) Surgical insertion of transmitters and telemetry methods in fisheries research 2014. Am J Vet Res 75:402-416

Russell WMS, Burch RL (1959) The principles of humane experimental technique. Methuen, London

Sigourney DB, Horton GE, Dubreuil TL, Varaday AM, Letcher $\mathrm{BH}$ (2005) Electroshocking and PIT tagging of juvenile Atlantic salmon: are there interactive effects on growth and survival? N Am J Fish Manag 25(3):1016-1021

Smircich MG, Kelly JT (2014) Extending the 2\% rule: the effects of heavy internal tags on stress physiology, swimming performance, and growth in brook trout. Anim Biotelem 2(1): 16

Smyth B, Nebel S (2013) Passive integrated transponder (PIT) tags in the study of animal movement. Nat Educ Knowl 4(3):3

Spares AD, Stokesbury MJ, O’Dor RK, Dick TA (2012) Temperature, salinity and prey availability shape the marine migration of Arctic char, Salvelinus alpinus, in a macrotidal estuary. Mar Biol 159(8):1633-1646

Strøm JF, Thorstad EB, Hedger RD, Rikardsen AH (2018) Revealing the full ocean migration of individual Atlantic salmon. Anim Biotelem 6(1):2

Thorstad EB, Rikardsen AH, Alp A, Økland F (2013) The use of electronic tags in fish research-an overview of fish telemetry methods. Turk J Fish Aquat Sci 13:881-896

Tiffan KF, Perry RW, Connor WP, Mullins FL, Rabe CD, Nelson DD (2015) Survival, growth, and tag retention in age-0 Chinook Salmon implanted with 8-, 9-, and 12-mm PIT tags. N Am J Fish Manag 35(4):845-852
Vandenabeele SP, Shepard ELC, Grémillet D, Butler PJ, Martin GR, Wilson RP (2015) Are bio-telemetric devices a drag? Effects of external tags on the diving behaviour of great cormorants. Mar Ecol Prog Ser 519:239-249

Verspoor E, Stradmeyer L, Nielsen JL (eds) (2008) The Atlantic salmon: genetics, conservation and management. Wiley, New York

Walker KA, Trites AW, Haulena M, Weary DM (2012) A review of the effects of different marking and tagging techniques on marine mammals. Wildl Res 39(1):15-30

Walton I (1653) The compleat angler. Richard Marriot, London

Welch DW, Batten SD, Ward BR (2007) Growth, survival, and tag retention of steelhead trout $(O$. mykiss) surgically implanted with dummy acoustic tags. In: Almeida PR, Quintella BR, Costa MJ, Moore A (eds) Developments in fish telemetry. Springer, Dordrecht, pp 289-299

Wendelaar Bonga SE (1997) The stress response in fish. Physiol $\operatorname{Rev} 77(3): 591-625$

Winter JD (1996) Advances in underwater biotelemetry. In: Murphy BR, Willis DW (eds) Fisheries techniques, 2nd edn. American Fisheries Society, Bethesda, Maryland, pp 555-590

Woodley CM, Carpenter SM, Carter KM, Wagner KA, Royer IM, Knox KM et al (2011) Surgically implanted JSATS micro-acoustic transmitters effects on juvenile Chinook Salmon and steelhead tag expulsion and survival, 2010. Pacific Northwest National Laboratory, Richland

Wright DW, Stien LH, Dempster T, Oppedal F (2019) Differential effects of internal tagging depending on depth treatment in Atlantic salmon: a cautionary tale for aquatic animal tag use. Curr Zool 65(6):665-673

Publisher's Note Springer Nature remains neutral with regard to jurisdictional claims in published maps and institutional affiliations. 